\title{
Development of intense, long-lived positron sources
}

\author{
T.D. Steiger ${ }^{1)}$, J. Stehr ${ }^{1)}$, H.C. Griffin ${ }^{2)}$, J.H. Rogers ${ }^{1) *}$, M. Skalsey ${ }^{1)}$ and J. Van House ${ }^{1)}$ \\ ") Randall Laboratory of Physics, Unwersity of Michigan, Ann Arbor, MI 48109, USA \\ ${ }^{2}$ Department of Chemistry, University of Michigan, Ann Arbor, MI 48109, USA
}

\begin{abstract}
There are many important applications for very intense positron beams ( $\geq 1 \mathrm{Cl}$ of $\mathrm{e}^{+}$), however, the radioactive sources needed to produce these beams are not readily available. Two separate processes for fabricatıng inexpensive, intense positron sources from ${ }^{22} \mathrm{Na}$ and ${ }^{58} \mathrm{Co}$ have been investıgated. Both procedures have been successfully tested with low levels (mC1) of activity.
\end{abstract}

\section{Introduction}

In recent years slow positron beam physics has become a very active and diverse field [1]. Currently under consideration are several applications of slow positron beams which require intense beams $\left(\geq 1 \mathrm{Ci}\right.$ of $\left.\mathrm{e}^{+}\right)$for their success. A partial list of such applications includes: the production and study of antihydrogen [2], the use of positrons in synchrotron light sources [3], positron microscopy [4], laser spectroscopy of positronium atoms [5], and the production of positron/ electron plasmas [6]. As a result there has been a great deal of interest in the production of very intense positron sources. Schemes for producing positron sources from several different isotopes have been considered, including ${ }^{48} \mathrm{~V}[7],{ }^{64} \mathrm{Cu}[8],{ }^{68} \mathrm{Ga}[9]$, and ${ }^{126} \mathrm{I}[10]$. In addition, methods of constructing intense positron beams using electron cooling [11] and bremsstrahlung from electron LINACs [12] have been investigated.

For small-scale laboratory experiments requiring intense positron beams, radioactive sources are the only feasible option. An important parameter to consider when choosing an isotope for a positron source is the half-life. Isotopes with long half-lives are preferred because they need to be replaced infrequently, which minimizes radiation exposure during handling. Of the useful positron emitters the two with the longest halflives are ${ }^{22} \mathrm{Na}$ (2.6 years) and ${ }^{58} \mathrm{Co}$ (71 days). Two separate projects have been undertaken at the University of Michigan aimed at developing processes for the fabrication of intense positron sources from both of these isotopes.

Positron sources made from ${ }^{22} \mathrm{Na}$ are very attractive for laboratory use because ${ }^{22} \mathrm{Na}$ combines a long halflife with high positron emission $\left(f\left(\beta^{+}\right)=90 \%\right)$. Although other schemes for producing ${ }^{22} \mathrm{Na}$ have been

\footnotetext{
* Current address: Axıc, Inc., Santa Clara, CA 95051, USA.
}

considered [13], the primary technique for producing large amounts of the isotope involves bombarding pure Al with high-energy protons from the LAMPF accelerator. The ${ }^{22} \mathrm{Na}$ is produced via various spallation reactions, e.g. ${ }^{27} \mathrm{Al}(\mathrm{p}, \mathrm{d} \alpha)^{22} \mathrm{Na}$.

Sealed ${ }^{22} \mathrm{Na}$ sources of moderate intensity are commercially available. However, since the primary use for ${ }^{22} \mathrm{Na}$ is medical tracer testing [14], positron yield is not particularly important to the manufacturers. As a result the specific activity $-\mathrm{e}^{+}$emitted per gram of source material - of commercial sources tends to vary greatly and is generally low [15]. Also, very intense sealed ${ }^{22} \mathrm{Na}$ positron sources are not available from commercial suppliers and the cost of separated activity to make such sources is prohibitively high [16].

The low and erratic specific activity of commercial sources could be caused by contaminants introduced during processing. Conventional chemical methods for separating $\mathrm{Na}$ from $\mathrm{Al}$ involve large quantities of reagents. Even a small amount [ppm] of sodium contamination in these reagents will introduce enough stable sodium to significantly dilute the ${ }^{22} \mathrm{Na}$. Physical separation processes - distillation, fractional crystalization, etc. - avoid contamination during separation by using no reagents. Presented below is a detailed discussion of an inexpensive process to distill $\mathrm{Na}$ from $\mathrm{Al}$ for use in intense positron sources [17].

Practical considerations such as the transportation of high activity sources and the availability of accelerators effectively put an upper limit on the achievable intensity of ${ }^{22} \mathrm{Na}$ sources. This limit is on the order of $1-10$ $\mathrm{Ci}$. For applications requiring more activity the best alternative is ${ }^{58} \mathrm{Co}\left(f\left(\beta^{+}\right)=15 \%\right)$. ${ }^{58} \mathrm{Co}$ can be produced in a reactor via the reaction ${ }^{58} \mathrm{Ni}(\mathrm{n}, \mathrm{p}){ }^{58} \mathrm{Co}$. The upper limit on ${ }^{58} \mathrm{Co}$ production is two to three orders of magnitude greater than the limit on ${ }^{22} \mathrm{Na}$ production because the flux of neutrons in a reactor is much greater than the flux of protons in an accelerator. As with ${ }^{22} \mathrm{Na}$, 
${ }^{58}$ Co sources are commercially available. These commercial sources have quality control problems similar to those of ${ }^{22} \mathrm{Na}$ sources and are not sealed in a permanent way. A general technique for producing intense ${ }^{58} \mathrm{Co}$ sources can be found in the literature [18]. Specific adaptations of this process which include encapsulation of the source are presented below.

The prumary motivation for both source production projects is simple economics. The sodium work is further motivated by a desire for higher quality and higher intensity sodium sources than are currently available. Other factors being equal, the long half-life of ${ }^{22} \mathrm{Na}$ makes it preferable to ${ }^{58} \mathrm{Co}$. The cobalt work is being pursued because of a desire for higher intensity sources than the sodium process can reasonably produce. Another advantage of cobalt over sodium is the fact that reactor irradiations are much less expensive than those performed at accelerators. Each process is discussed separately.

\section{Theoretical considerations of sodium distillation}

The feasibility of distilling sodium from aluminum was demonstrated many years ago [19]. An elementary understanding of this phenomenon may be gained through a consideration of the low mutual solubility of the two elements and their respective vapor pressures at the melting point of $\mathrm{Al}$. The $\mathrm{Al}-\mathrm{Na}$ phase diagram (fig. 1) indicates that sodium has little tendency to remain in molten alumınum [20]. At the monotectic point a solution of liquid $\mathrm{Al}$ saturated with $\mathrm{Na}$ is in equilibrium with a solution of liquid $\mathrm{Na}$ saturated with Al. However, the solubility of $\mathrm{Al}$ in $\mathrm{Na}$ is small enough that the vapor pressure of the sodium in the latter solution can be taken to be that of pure sodium [21]. The vapor pressure of pure $\mathrm{Na}$ at this temperature is about 66 Torr [22]. Thus, a liquid solution of Al which 1s saturated with $\mathrm{Na}$ has a sodium concentration of $0.14 \%$ (see fig. 1) and is in equilıbrium with 66 Torr of sodium vapor. The vapor pressure of $\mathrm{Al}$ at its melting point is on the order of $10^{-10}$ Torr [23], indicating that sodium can be effectively distilled from a saturated Al- $\mathrm{Na}$ system.

The concentration of $\mathrm{Na}$ produced by proton bombardment is well below saturation and thus the vapor pressure of this $\mathrm{Na}$ is well below 66 Torr. A curie of ${ }^{22} \mathrm{Na}(0.16 \mathrm{mg})$ in an $\mathrm{Al}$ target of appropriate size (e.g. $6.35 \mathrm{~cm}$ diameter $\times 2.54 \mathrm{~cm}$ ) results in a sodium concentration of only $1.5 \mathrm{ppm}$ (taking into account the fact that the spallation reactions produce stable ${ }^{23} \mathrm{Na}$ at about the same rate as ${ }^{22} \mathrm{Na}$ ). Since the sodium concentration is low, the sodium atoms are treated as independent. Hence the relationship between $\mathrm{Na}$ concentration and $\mathrm{Na}$ vapor pressure is taken to be linear to fair approximation and, therefore, the vapor pressure

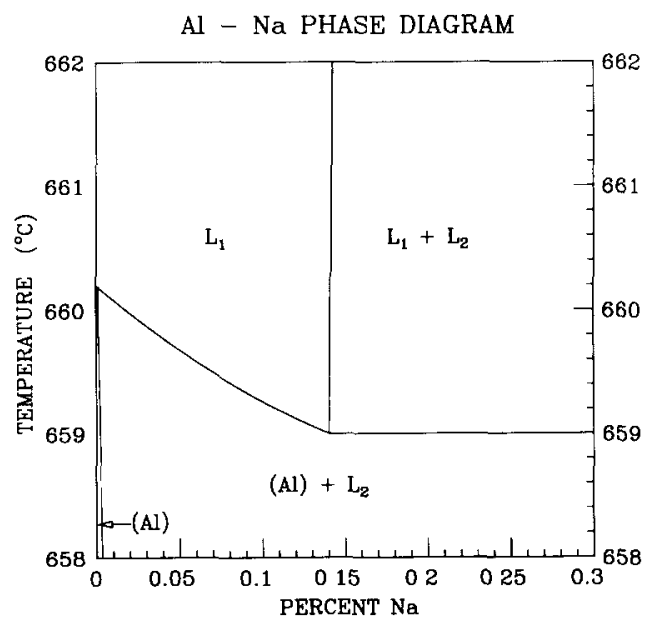

Fig. 1. The alumunum-sodium phase diagram. $\mathrm{L}_{1}, \mathrm{~L}_{2}$ and (Al) are three distinct phases with variable compositions. $L_{1}$ is liquid $\mathrm{Al}$ which contains some $\mathrm{Na} . \mathrm{L}_{2}$ is liquid $\mathrm{Na}$ whech contains a trace amount of $\mathrm{Al}$ and is treated as pure $\mathrm{Na}$ in the discussion. If $L_{2}$ is present, then $L_{1}$ is saturated with $\mathrm{Na}$. (Al) is the solid phase; it is almost pure Al but contains $\mathrm{Na}$ to the extent that $\mathrm{Na}$ is soluble in solid $\mathrm{Al}$ at temperatures near the melting point of Al. Redrawn from ref. [21].

for a given concentration is estimated by comparison to the saturated solution. The vapor pressure corresponding to a concentration of $1.5 \mathrm{ppm}$ is about $70 \mu \mathrm{m}$. This is still much higher than the vapor pressure of aluminum $\left(\sim 10^{-4} \mu \mathrm{m}\right.$ ), indicating that distillation is still feasible for suitably low $\mathrm{Na}$ concentrations.

The above considerations are sufficient for a clean metal-vacuum interface, but the aluminum is enclosed in a tough oxide layer which remains largely intact throughout the process. This layer of $\mathrm{Al}_{2} \mathrm{O}_{3}$ could potentially present a physical barrier to the sodium and prevent the distillation. This issue has been carefully studied by ion beam physicists who use molten metal targets in their ion sources [24]. Whule an oxide layer does tend to slow the rate of distillation it does not make distillation impossible. By comparison to similar molten metal systems it is concluded that the excess time a sodium atom spends in the aluminum due to the oxide layer is on the order of tens of seconds at most [24]. Thus the oxide layer is not a concern and distillation is a viable method for removing trace amounts of sodium from aluminum.

\section{Sodium separation apparatus and procedure}

Several systems have been built to test the details of the sodium distillation process. The basic design considerations are common to all of the systems used. Fig. 2 is a schematic which illustrates the important points. 


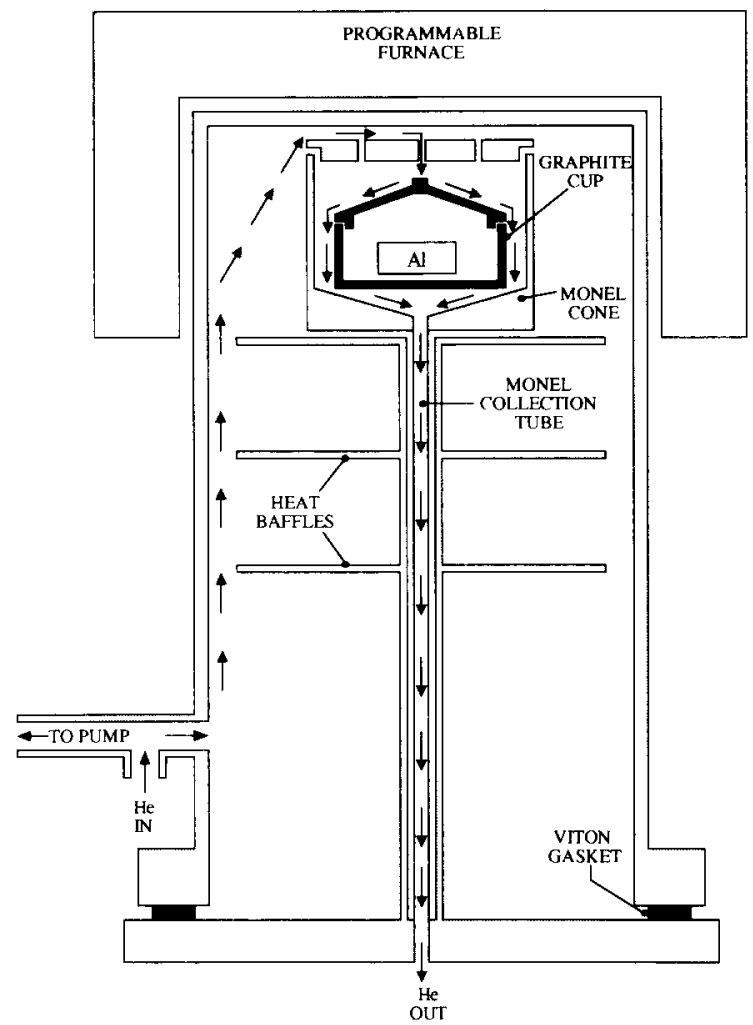

Fig. 2 Sodium distillation apparatus. The Al sample is melted and any ${ }^{22} \mathrm{Na}$ it contains is distlled out. The sodium vapor passes through the graphite crucible and is directed into the collection tube by the flowing $\mathrm{He}$ gas. The lower portion of the collection tube remains relatively cool due to the heat baffles and the Na plates out on the inner surface of this tube. Monel is used for most of the construction because sodium does not react strongly with it.

Since the goal of the process is to isolate sodium, the first consideration is the use of materials which do not interact strongly with the very reactive sodium. For this reason the apparatus is constructed almost entirely of monel - a nickel alloy containing about 30\% copper. Sodium does not stick to monel significantly even at temperatures up to $300^{\circ} \mathrm{C}$ [25]. This property greatly simplifies the collection of the sodium. In traditional procedures the distillation must be followed by a significant amount of chemical processing [19]. In the current procedure the product can be retrieved with a small amount of water. In the event of a mishap the monel construction would also simplify the decontamination of the apparatus.

Unfortunately molten aluminum forms an alloy with monel from which the sodium cannot be removed. Hence the Al sample cannot be allowed to come into contact with the monel - another material must be used to support the aluminum. Graphite was chosen for this task because it does not react with either $\mathrm{Al}$ or $\mathrm{Na}$.
Graphite is very porous and is permeable to the sodium vapor. However, it is well known that graphite does not trap sodium at high temperatures [26] and so the sodium passes directly through the graphite crucible with relative ease.

The next design consideration is the collection of the sodium vapor once it leaves the aluminum. Distillations of this sort are usually performed in a vacuum [19]; however, an inert gas atmosphere at ambient pressure is utilized in the present work. This high pressure scheme was motivated by preliminary tests which were performed in an evacuated bell jar. These tests indicated that vapor released into a vacuum uniformly coated the inside of the vacuum chamber, which complicated the collection of the sodium. The flowing $\mathrm{He}$ gas was introduced to improve control over the location of the sodium.

There was initial concern over the possibility that trace amounts of $\mathrm{O}_{2}$ in the $\mathrm{He}$ would affect the distillation of $\mathrm{Na}$. This concern was largely eliminated by a reference to an inefficient separation technique which had been used in the past and involved melting the $\mathrm{Al}$ in air [20]. The result of this technique was that the $\mathrm{Na}$ migrated to the surface of the Al where it could be easily etched into a solution. Thus, if there were serious $\mathrm{O}_{2}$ contamination, the worst possible consequence would be a need to etch the Al after a separation to improve the yield. Such etching has not been found to be necessary. During ambient pressure distillations the $\mathrm{He}$ gas performs two useful functions: first it sweeps the $\mathrm{Na}$ vapor away from the $\mathrm{Al}$, thereby preventing the speed of the process from being limited by diffusion, then it directs the $\mathrm{Na}$ into the collection tube.

A strong thermal gradient is maintained by heat baffles so that the bottom of the collection tube remains near room temperature. As a result, any sodium vapor which enters the tube is exposed to a cool surface before leaving the apparatus. The $\mathrm{Na}$ plates out on this surface and the product of the process - a small amount of sodium-containing solution - is then rinsed from the collection tube. This collection geometry is advantageous because the tube provides a large surface area for collection which can be washed with a small volume of liquid. Minimizing the volume of the product solution reduces the amount of contamination introduced by the process, simplifies any subsequent chemical purification which may be necessary, and speeds the source deposition process.

Once the ${ }^{22} \mathrm{Na}$ solution has been washed from the monel collection tube it may be purified by use of an ion exchange column. After purification the solution is allowed to dry and a small amount of dilute hydrofluoric acid is added. The resulting radioactive solution of sodium fluoride is again allowed to dry and the residual salt is dissolved in water. This aqueous solution is drawn into a hypodermic needle. A precision stepper 
motor is connected to the plunger which allows the solution to be expelled one drop at a time. The solution is deposited onto a tungsten backing which has had a thin disk of dried insulin deposited upon it. The insulin acts as a wetting agent and therefore the diameter of the insulın spot defines the size of the positron source. Each drop is allowed to evaporate before the next drop is deposited. Once all of the sodium fluoride solution has been deposited and dried, the source is sealed behind a thin nickel window and is ready for use.

Numerous tests of the distillation process have been performed utilizing trace amounts of ${ }^{24} \mathrm{Na}$ - an isotope with a short half-life (15 h). Typically a few grams of $99.999 \%$ pure $\mathrm{Al}$ are irradiated for $10-20 \mathrm{~min}$ in the core of the University of Michigan's Ford Nuclear Reactor yielding $50-100 \mu \mathrm{Ci}$ of ${ }^{24} \mathrm{Na}$. After irradiation various short-lived aluminum isotopes must be allowed to decay for approximately two hours, after which ${ }^{24} \mathrm{Na}$ is the only radio-isotope visible in an energy spectrum taken with a Ge detector. This purity allows all of the necessary data to be collected with a $\mathrm{NaI}$ detector and a counter. The relative fraction of sodium which is present on any given object may be determined by comparing simple count rates.

Before a test the outlet of the collection tube is blocked allowing the system to be pumped down to $\sim 50-100 \mu \mathrm{m}$ with a rotary pump and then brought up to atmospheric pressure with helium. This procedure is repeated several tımes to minimize the amount of oxygen present during the test. The desired flow of He (typically $-450 \mathrm{ml} / \mathrm{min}$ ) is then established and the heaters are turned on. The temperature is monitored via chromel-alumel thermocouples. Tests have been run at temperatures ranging from $650^{\circ}$ to $1100^{\circ} \mathrm{C}$ and for durations ranging from $30 \mathrm{~min}$ to $6 \mathrm{~h}$. After a test the apparatus must be allowed to cool down for $-2-3 \mathrm{~h}$ to prevent excessive oxidation of the monel interior when the system is opened to air.

The duration of the tests is a large enough fraction of the ${ }^{24} \mathrm{Na}$ half-life that the count rates taken afterwards must be corrected for decay. The distillation efficiency is obtained by simply comparing the count rate of the $\mathrm{Al}$ sample before the test to its corrected rate after the test. The collection efficiency is obtained by disassembling the apparatus and counting each piece separately. Generally all of the activity which is initially in the aluminum can be accounted for after each test.

While being counted all samples are placed at a fixed position inside a large lead cannister which also contains the Nal detector. The irregularity of the detection geometry due to the disparate sizes and shapes of the pieces causes a discrepancy between the measured inıtial count rate and the sum of the final count rates. This discrepancy is typically only a few percent, which is small enough that reasonably accurate location of the sodium is possible using this simple method.

\section{Sodium results}

Tracer amounts of ${ }^{24} \mathrm{Na}$ have been used to perform exhaustive tests of the process described above. Factors such as the temperature and duration of the distillation as well as the geometry of the collection apparatus have been optimized. A $2-4$ hour bake at $\sim 1050^{\circ} \mathrm{C}$ has been found to work best. The preferred geometry is illustrated in fig. 2 . The result of this optimization is a process which is efficient enough to be economically advantageous.

The separation of the sodium from the aluminum is very efficient. More than $90 \%$ of the $\mathrm{Na}$ is routinely removed and occasionally $>99 \%$ separation is achieved. However, the collection of the separated sodium vapor is somewhat less efficient. Under the proper conditions $50-70 \%$ of the initual sodium activity may be expected to plate out in a small region of the collection tube. Because the collection tube is made of monel, all of the sodium collected may be removed with water, provided that the temperature of the tube does not exceed $600-$ $700^{\circ} \mathrm{C}$ during the distillation. In tests run without heat baffles on the collection tube, $\mathrm{HCl}$ was necessary to remove some of the sodium and $-15 \%$ of the activity was 1rrecoverable even with acid. It is expected that the overall efficiency will not decrease significantly durng the scale-up to curies of activity and hence up to $70 \%$ of the ${ }^{22} \mathrm{Na}$ produced in an irradiated aluminum block may be recovered and deposited as a positron source using this method. Such high efficiency is important because of the great cost of the initial proton bombardment.

In addition to the ${ }^{24} \mathrm{Na}$ tests a ${ }^{22} \mathrm{Na}$ separation has been performed using millicuries of activity from a LAMPF activation. The separation and collection efficiencies of the ${ }^{24} \mathrm{Na}$ runs were reproduced. The result was a solution containing $7.4 \mathrm{mCi}$ of ${ }^{22} \mathrm{Na}$. A $1.65 \mathrm{mCi}$ positron source was deposited directly from this solution, omitting purification. The specific activity of this source was unacceptably low, indicating significant contamination. For future separations greater attention will be paid to the cleanliness of the separation apparatus and a purification step will be added between separation and deposition.

\section{Cobalt source production}

The fast neutron reaction ${ }^{58} \mathrm{Ni}(\mathrm{n}, \mathrm{p}){ }^{58} \mathrm{Co}$ can be used to produce ${ }^{58} \mathrm{Co}$. Natural nickel may be used as the target material since it contains $68 \%{ }^{58} \mathrm{Ni}$. After the irradiation the nickel sample is dissolved in acid. The cobalt is then chemically separated from the nickel in the acid solution by ion-exchange chromatography. Finally, a positron source is produced by electroplating the ${ }^{58} \mathrm{Co}$ in thin layers onto a metallic backing [27]. 
The first step in this process - activating the nickel samples - has been investigated using various activation sites in the Ford Reactor. The best results were obtained with irradiations done directly in the reactor core at points where the fast neutron flux is maximized by excluding water from the vicinity. The process has been optimized for yield and purity of the ${ }^{58} \mathrm{Co}$ and for size of the nickel samples. Under optimal conditions, the expected rate of production is $0.15 \mathrm{Ci}$ of ${ }^{58} \mathrm{Co}$ per gram of nickel. One fuel rod can be replaced by $18 \mathrm{~kg}$ of nickel without adversely affecting the operation of the reactor. The irradiation of this amount of $\mathrm{Ni}$ would yield $-200-300 \mathrm{Ci}$ of $\mathrm{e}^{+}$.

An important consideration in optimizing ${ }^{58} \mathrm{Co}$ production is the depletion of the desired product by thermal and fast neutrons. This "burn-up" of ${ }^{58} \mathrm{Co}$ during production has been investigated by irradiating a series of samples for increasing lengths of time. The growth of ${ }^{58}$ Co activity $A$ is given by

$A=A_{\max }\left[1-\exp \left(-\lambda_{\text {tot }} t\right)\right]$,

where $\lambda_{\text {tot }}=\lambda_{\text {decay }}+\lambda_{\text {burn-up }}$.

The difference between $\lambda_{\text {tot }}=1.31 \times 10^{-3} \mathrm{~h}^{-1}$ and $\lambda_{\text {decay }}=\ln 2 / T_{1 / 2}=4.07 \times 10^{-4} \mathrm{~h}^{-1}$ is quite evident in the measurements. The value for $A_{\max }$ obtained is 0.224 $\mathrm{Ci} / \mathrm{g} \mathrm{Ni}$, indicating that a 5 week activation would result in a product with $0.15 \mathrm{Ci} / \mathrm{g} \mathrm{Ni}$. In an effort to reduce burn-up due to thermal neutrons, the Ni samples were cladded with cadmum foil. Surprisingly, cladding with foil thick enough to stop $>99 \%$ of the thermal neutrons did not affect the activation, indicating that the burn-up is primarily due to epicadmium neutrons.

The Ford Reactor has also been used to analyze several samples of commercial nickel foils to determine the initial cold Co contamination. The activation of 0.15 $\mathrm{Cl}_{1}$ of ${ }^{58} \mathrm{Co}$ in $1 \mathrm{~g}$ of nickel implies a ${ }^{58} \mathrm{Co}$ concentration of only $4.7 \mathrm{ppm}$. Clearly, the initial cold Co concentration of the $\mathrm{Ni}$ samples should be smaller than this to insure high specific activity for the ${ }^{58} \mathrm{Co}$. A result of $\leq 1$ ppm Co contamination was obtained for one nickel sample and $\approx 15 \mathrm{ppm}$ Co was obtained for another, less expensive, nickel sample. Thus, though natural nickel may be used, obtaining high quality $\mathrm{Ni}$ for the irradiation is essential to the success of the process.

After the activation of the nickel foils in the reactor core, the irradiated samples are transferred to a hot cell. Within the hot cell a separation apparatus which is suitable for remote manipulation has been built. This apparatus is designed to accomplish both the removal of the ${ }^{58} \mathrm{Co}$ from the nickel and the electroplating which yields the final positron source.

The steps in the chemical processing have been described by Sherief and Grass [18]. The first step is to use concentrated $\mathrm{HCl}$ to dissolve the nickel. Approximately $10 \mathrm{~g}$ may be dissolved in the separation apparatus overnight if the solution is heated. By maintaining a sufficiently high concentration of $\mathrm{Cl}^{-}$ions in the dissolving solution, the reaction

$\mathrm{Co}^{2+}+4 \mathrm{Cl}^{-} \Leftrightarrow\left(\mathrm{CoCl}_{4}\right)^{2-}$

is driven to the right. The fact that nickel does not form such an anion complex allows the ${ }^{58} \mathrm{Co}$ to be separated from the nickel ions. The solution from the dissolving chamber is slowly passed through a column of ion exchange resin. The resin holds anions (Co complexes) and passes cations (Ni). When the $\mathrm{Cl}^{-}$concentration is reduced (by adding water) the reaction in eq. (2) is driven to the left and the column of resin releases the cobalt.

The purified cobalt solution is directed into the electroplating cell and an electrolytic solution - described in ref. [18] - is also added. During the electroplating process, a helical $\mathrm{Pt}$ wire is used as an anode. The cathode - a thin circular rod - may be made from a variety of metals. The goal is to produce an adherent deposit in a circular spot of a few mm diameter.

The formation of gas bubbles on the cathode adversely affects the electroplating process. To prevent this the solution is vigorously agitated by a magnetic stirrer during deposition. Plating currents of a few $\mathrm{mA}$ are used to produce shiny, adherent deposits. After deposition the cathode is removed and rinsed with water. To provide a measure of containment in the event that the radioactive deposit flakes off, the cathode is placed in a cylindrical sleeve of stainless steel with a thin $\left(3 \mathrm{mg} / \mathrm{cm}^{2}\right)$ nickel window soldered to one end. This window will attenuate $<10 \%$ of the positrons.

Thus far, two sources of roughly 1 and $10 \mathrm{mCi}$ intensity, respectively, have been produced using this method. In both cases considerable absorption of positrons due to excessive source thickness was observed. The $\mathrm{e}^{+}$yield of the $10 \mathrm{mC}_{1}$ source was a factor of 5 smaller than expected. It is suspected that the $\mathrm{Ni}$ is not being completely removed in the on-exchange separation. $\mathrm{Ni}$ in the electroplating cell would cause a much thicker $\mathrm{e}^{+}$source to be produced resulting in reduced $\mathrm{e}^{+}$yields. Use of a two-column separation scheme is planned which is expected to enhance the ${ }^{58} \mathrm{Co}$ purity in the Ni separation step.

\section{Acknowledgements}

The authors would like to thank R. Burn, G. Cook, K. Conway and the staff of the Ford Nuclear Reactor for their roles in providing the radioactive samples used in these tests, and L.A. Denison for help in preparing the manuscript. The authors also acknowledge useful discussions with R. Conti, W. Frieze, D. Gidley, J.S. Nico and A. Rich. Commercial use of the sodium separation process described in this paper is governed by U.S. Patent \#4894208. This research has been 
supported by NSF grant PHY88-03718 and by a grant from the Office of the Vice President for Research of the University of Michigan.

\section{References}

[1] For reviews of positron beam physics see: A. Rich, Rev Mod. Phys. 53 (1981) 127;

P J. Schultz and K.G. Lynn, Rev. Mod. Phys. 60 (1988) 701.

[2] A. Ruch, R. Contı, W. Frieze, D.W. Gidley, H. Griffın, M. Skalsey, T. Sterger, J. Van House, W. Zheng and P.W. Zitzewitz, in: Atomic Physics with Positrons, eds. J.W. Humberston and E.A.G. Armour (Plenum, New York, 1987) p. 321.

[3] H. Winick, Sci. Am. 257 (Nov. 1987) 88.

[4] J. Van House and A. Rich, Phys. Rev. Lett. 60 (1987) 169.

[5] S. Chu and A.P. Mills Jr., Phys. Rev. Lett. 48 (1982) 1333.

[6] A.P Mills Jr., in: Positron Scattering in Gases, eds. J.W. Humberston and M.R.C. McDowell (Plenum, New York, 1984) p. 121

[7] G. Sinapius and H.L. Ravn, in: Atomic Physics with Positrons, eds. J.W. Humberston and E.A.G. Armour (Plenum, New York, 1987) p 185.

[8] K.G. Lynn and W.E Frieze, in: Positron Scattering in Gases, eds. J.W. Humberston and M.R.C. McDowell (Plenum, New York, 1984) p. 165.

[9] T.A. Girard, M Skalsey, E. Sweetman, D.E. Newman and A. Van der Molen, Nucl. Instr. and Meth. 205 (1983) 567.

[10] M. Skalsey and J Van House, Nucl. Instr. and Meth. B30 (1988) 211.

[11] D.J. Larson, Phys. Rev. Lett. 60 (1988) 1274.

[12] L.D. Hulett, Jr., T.A. Lewis, R.G. Alsmiller, Jr., R. Peelle, S. Pendyala, J.M. Dale and T.M. Rosseel, Nucl. Instr. and Meth. B24/25 (1987) 905
[13] B. Saam, M. Skalsey, and J. Van House, Phys. Rev. C40 (1989) R1563.

[14] C. Machett1, private communication.

[15] G.R. Massoumi, P.J. Schultz, W.N. Lennard and J. Ociepa, Nucl. Instr. and Meth. B30 (1988) 592.

[16] New England Nuclear has given quotes of $\$ 135000$ for 1 $\mathrm{C}_{1}$ and $\$ 500000$ for $10 \mathrm{Ci}$ of separated ${ }^{22} \mathrm{Na}$. They do not currently deposit and seal sources with activities higher than $150 \mathrm{mCl}$.

[17] A preliminary discussion of the ${ }^{22} \mathrm{Na}$ separation process was presented at the Symp. on the Production and Investigatıon of Atomic Antımatter, Kernforschungszentrum Karlsruhe, 1987. See. H.C. Griffin, T.D. Steiger, J. Van House, M. Skalsey R Conti, A. Rıch and P.W. Zitzewitz, Hyperfine Interactions 44 (1988) 147.

[18] M.K. Sherief and F. Grass, Atomkernenergie 21 (1973) 139.

[19] W McCamley, T.E.L. Scott and R. Smart, Analyst 76 (1951) 200.

[20] C.E. Ransley and H. Neufeld, J. Inst. Metals 78 (1950/ 1951) 25.

[21] M. Hansen and K. Anderko, Constitution of Binary Alloys (McGraw-Hill, New York, 1958) p. 117.

[22] G.V. Samsonov (ed.), Handbook of the Physicochemical Properties of the Elements (IFI/Plenum, New York, 1968) p. 252.

[23] D.E. Gray (ed.), American Institute of Physıcs Handbook (McGraw-Hill, New York, 1963) p. 4-286.

[24] H.L. Ravn, Phys. Rep 54 (1979) 201.

[25] L. Davis Jr., D.E. Nagle and J.R. Zacharias, Phys. Rev. 76 (1949) 1068.

[26] R. Klapisch, in: Nuclear Spectroscopy and Reactions, vol. A, ed. J. Cerny (Academic Press, New York, 1974) p. 213.

[27] J.H. Rogers and M Skalsey, Bull. Am. Phys Soc. 34 (1989) 1799. 